\title{
Process Design of Standardization Data for China 4PL Capital Management and Calculation Algorithm
}

\author{
Yan Zhang \\ Director of Logistics Institute SYU, \\ Science and Technology dept, \\ Shenyang University, Shenyang, China \\ E-mail: sdxinxi@126.com
}

\author{
Zhong-Hu Yuan \\ Shenyang University, \\ Shenyang, China \\ E-mail: syyzh62@163.com
}

\begin{abstract}
As problems of both low level informatization and intensification exist in China's TPL industry, a key way to improve logistics level should be the TPL increased informatiztion level. The author proposes the building of a 4PL platform based on the real needs of most TPL enterprises, which will benefit most TPLs. As a result, the TPL enterprises may share warehousing resources, freight resources and joint distribution. The standardized process of capital management in 4PL platform building is designed, being focused on the operation of capital management and settlement algorithm in the paper. Such treatments as shipping freight and capital management, shipping freight distribution algorithm, pick account operation are also accordingly provided.
\end{abstract}

Keywords-4PL; TPL; capital management; algorithm; standardized process

\section{INTRODUCTION}

China's third party logistics(TPL) still has approximately $6 \%-10 \%$ room to be improved, being compared with that of developed nations ${ }^{[1]}$. As we known, a key way to improve China's TPL is its increasing of informatization level, while the statistic fact shows that more than 700, 000 domestic registered TPL enterprises ${ }^{[2]}$ have only less than $10 \%{ }^{[2]}$ proportion of informatization. Based on this, Wang Yang, vice premier of the State Council pointed out that Logistics industry is the basic and strategic industry to support the development of the national economy and society. National Development and Reform Commission will enhance the logistics industry information, standardization level as the main task ${ }^{[3]}$.4PLplatform building may reduce both traction and commodity transferring costs, simplify logistical process, thus bringing tremendous social cost reduction as well as profit increasing ${ }^{[4]}$. This view has gained common understanding in this industry.

The author proposes building such a 4PL management platform that, together with the building of a standardized process, which will serve a number of TPL, ensure a sound management of each TPL's branches, and fit the business reality and at the same time, also ensure the TPL enterprises and their branches to benefit from cloud logistics on the Web, with which TPL enterprises can manage themselves through the platform at the lowest cost ${ }^{[5-7]}$. The standardized process of capital management in 4PL platform building is designed, being focused on the operation of capital management and settlement algorithm in the paper. Meanwhile, on the basis of the standardization process of inbound and outbound delivery operations ${ }^{[8-9]}$, the discussions in the paper are focused on such items as operation of outbound lists transfer, outbound balance lists transfer, shipping freights distribution by weight, shipping freights distribution by volume, shipping freights distribution by income, pick account operation, and algorithm.

\section{DELIVERY AND CAPITAL MANAGEMENT PROCESS}

\section{A. Outbound Lists Transfer}

The actual sample "Outbound lists" see Table 1. In the "Outbound lists" the "From..." is to be filled in the delivery city by the system automatically, "To..." generated according to the "Destination" of "inventory table " , "yy-mm-dd" automatically generated on the day. The main data include " Inbound date ", "Number of inbound list", " Name of shipping enterprise" " Receiving enterprise name ", "Name of goods", "Weight" , "Volume", " Number of packages ", "The order arrival day", " Order number ", "Library single quantity", " Collected at destination ", "Self pick up", "Collection payment ", which are generated from " Inventory table ". "Invoice number" will be generated by the system automatically. The " Remarks " system should be generated and content to fill in the manual. "The library staff (Lister)", "Warehouse keeper", "Delivery ", "Handling" be generated by the system automatically. "Consignee", "The actual delivery date" is to be filled in by destination consignee. "Actual delivery" is filled in based on the actual transport agreement from delivery handling, If the data are filled in terms of weight and volume, then the amount should be less than or equal to the total item, that is Actual shipping weight $\leqslant \sum$ A single order number of weight, and actual shipping volume should be $\leqslant \sum$ A single order number of volume.

\section{B. Outbound Balance Lists Transfer}

When the "Daily settlement tables ${ }^{[10]}$ "is created, having only the "Receiving freight ", and after the goods form the origin signing of the transport agreement, the "Shipping freight " will be generated. The delivery will propose transport agreement to the general accounting office for the audit of the transport agreement. Since then, The delivery transports a single copy of the agreement and a " Outbound lists " to the distribution (or driver). The distribution (or driver) will bring the" Outbound lists " to the inventory 
manager to loading the goods and will be delivered, after that the transport agreement will be sent to the cashier. If the "Shipping freight " is cash, the distribution can cash at the cashier. The cashier fills cash in "Daily settlement tables". If the "Shipping freight" is account period, the distribution will sign at the cashier. The cashier fills "Account period" in " Daily settlement tables".

TABLE I. OUTBOUND LISTS

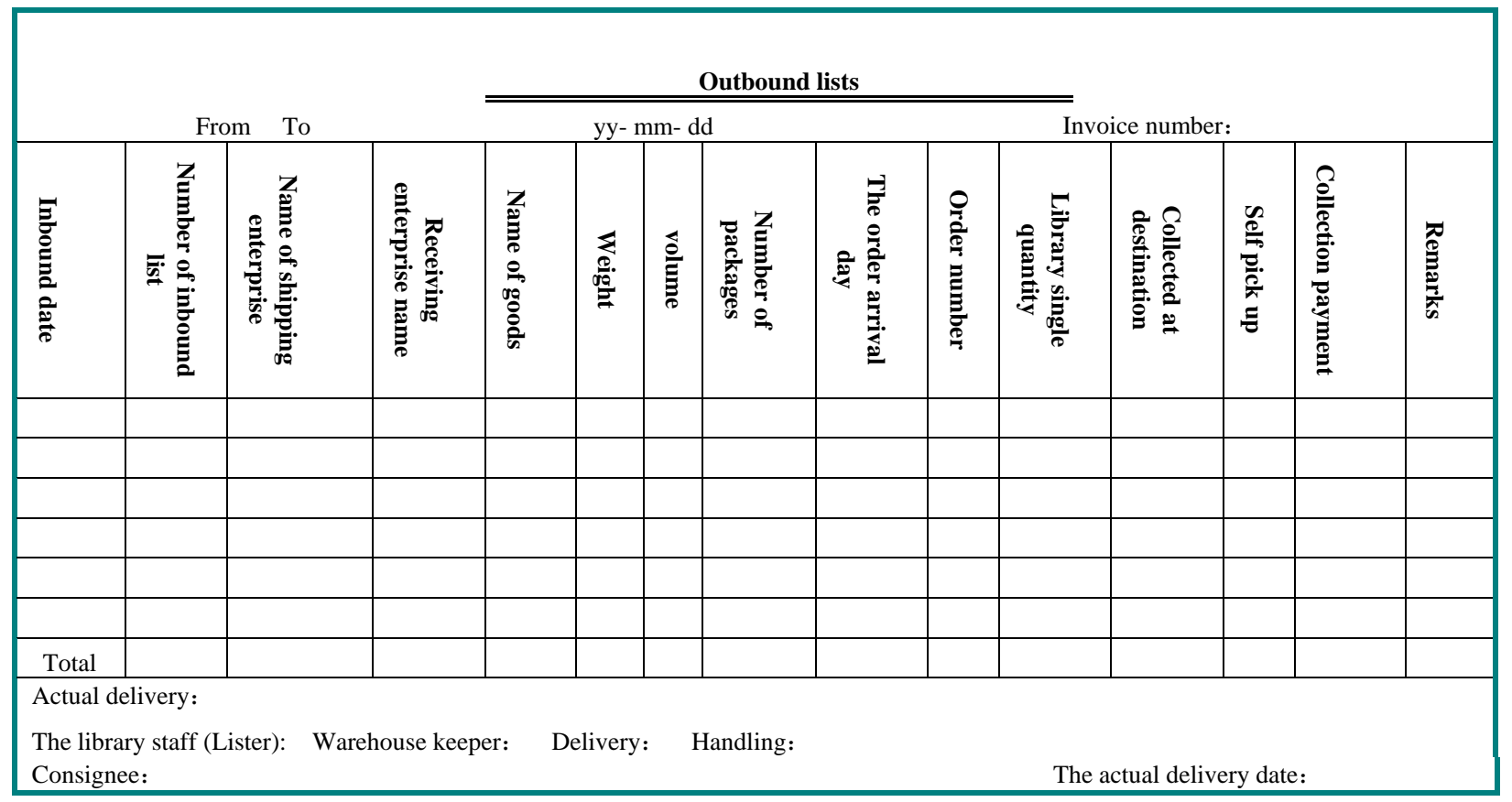

For cashier fill "Daily settlement tables" easily, the electronic "Outbound balance lists" is generating as shown in table 2. The table 2 is a temporary table. Such items as "From...", "To...", " yy-mm-dd ", " Invoice number "," Number of inbound list ", " Name of shipping enterprise ", "Weight" , "Volume", " Number of packages ", " Arrival pay ", " Actual delivery", "The library staff (Lister) ", "Warehouse keeper"," Delivery "," Handling ", "Consignee", "The actual delivery date" will be generated according to "Outbound lists".

The items "Average piece ", "Cash" "Account period", "Other charges", "Total " under "Receiving freight" are generated according to " inventory table " automatically. The "Account period " is the " Account period " and "Back pay" in "inventory table". Under " Shipping freight", the "Average piece " is calculated as " Total " of " Shipping freight"/ "Number of packages" automatically. "Cash", "Account period" is written in by the cashier accordance with the transport agreement; "Total" is "Cash" and "Account period" automatic calculation. "Total" amount should be less than or equal to the "Total" amount of the "Receiving freight" /3; If it is greater than the "Receiving freight" /3 system prompt, being not allowed to write in. The last line of the "Total" is automatic display. The value that cashier fills in is transferred into the " Daily settlement table", before that it should be prompted to confirm" The outbound balance lists is transferred into the daily settlement table". After that cashier cannot change the transfer date in the" Daily settlement table", If it needs to be changed, it should be reported to the general manager of the branch for approval.

\section{SHIPPING FREIGHTS DISTRIBUTION}

If the goods are integrated as a whole in the vehicle as well as the whole vehicle delivery, the shipping freight is directly filled into the the value of shipping agreement. When multiple number of inbound list goods are distributed in the same car, we need to divide the shipping freight into each number of inbound list goods, in other words, that is distributed in shipping freights. This is also to fill the shipping freight of outbound in balance lists, which functions as a multiple number of inbound list goods corresponding to an single invoice number, distributed in the same car. The shipping freights distribution have a variety of algorithm ways. If the actual shipping freight is $\mathrm{F}_{0}$, The mass of number of inbound list is $n$, any one is $\mathrm{i}$, the singular number is $1 \ldots \mathrm{i} . . . \mathrm{n}$. Receiving volume respectively are as in (1).

$$
\text { V1... Vi... Vn. }
$$

Receiving weight respectively are as in (2).

$$
\text { W1... Wi... Wn. }
$$




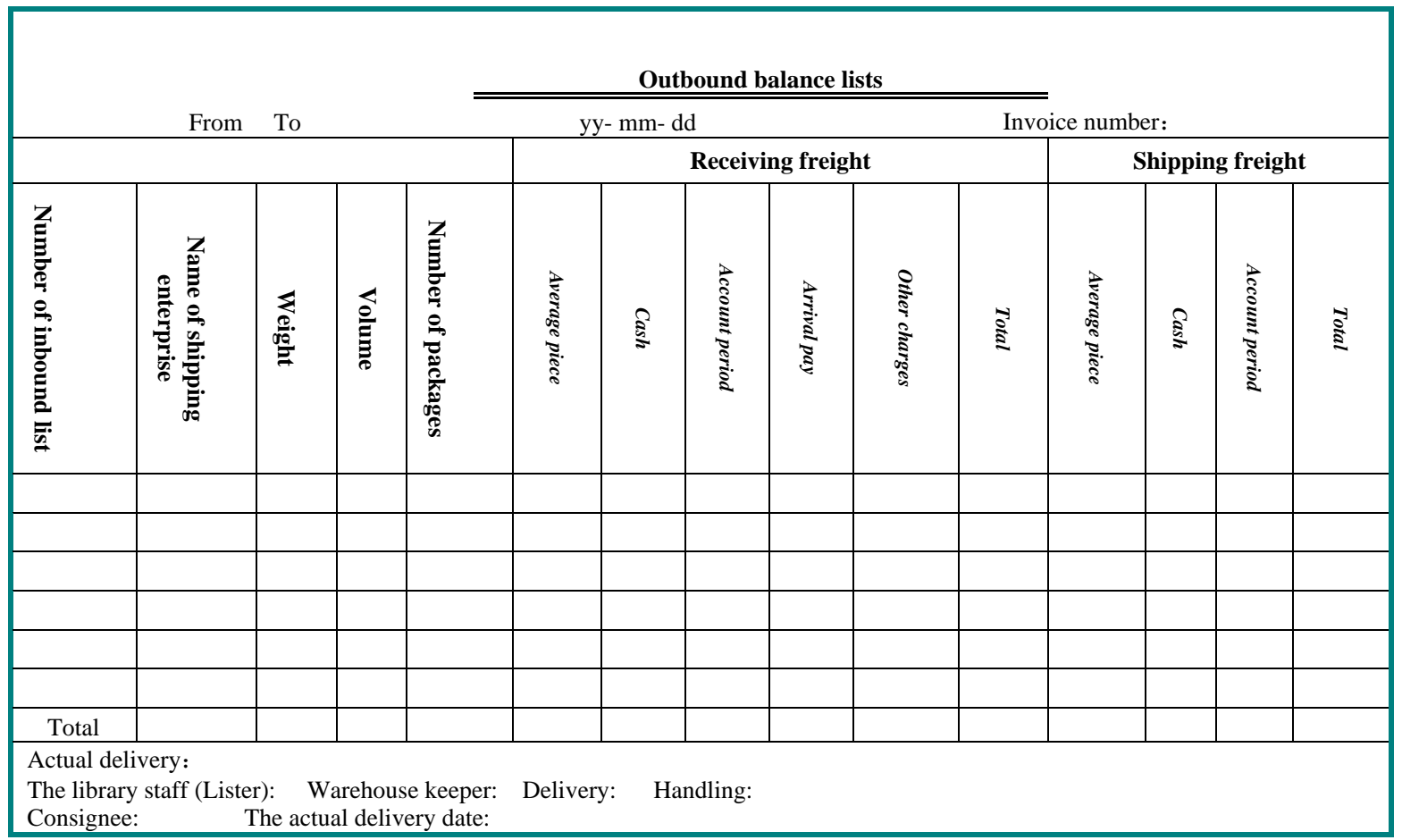

\section{A. Shipping Freights Distribution by Weight}

The shipping freights distributed by weight respectively are: $\mathrm{WF}_{1} \ldots \ldots . \mathrm{WF}_{\mathrm{i}} \ldots \ldots . \mathrm{WF}_{\mathrm{n}}$, shown as in (3). The disadvantage is that, the delivery freight is relatively less than it should be, while these freights have different cost calculation ways in terms of delivery and receiving.

$$
\mathrm{WF}_{\mathrm{i}}=\mathrm{F}_{0} \times \mathrm{W}_{\mathrm{i}} / \sum_{i=1}^{n} \mathrm{~W}
$$

\section{B. Shipping Freights Distribution by Volume}

The shipping freight distributed by volume respectively are: : $\mathrm{VF}_{1} \ldots \ldots \mathrm{VF}_{\mathrm{i}} \ldots \ldots . \mathrm{VF}_{\mathrm{n}}$ as in (4). The disadvantage is that, the delivery freight is relatively less than it should be, while these freights have different cost calculation ways in terms of delivery and receiving.

$$
\mathrm{VF}_{\mathrm{i}}=\mathrm{F}_{0} \times \mathrm{V}_{\mathrm{i}} / \sum_{i=1}^{n} V
$$

\section{Shipping Freights Distribution By Weight Volume Ratio}

The shipping freights distribution through weight or volume is determined according to table 1 in the "actual delivery" . The advantage of such a choice is easy to calculate, the disadvantage is less reasonable. Shipping freights distribution by weight volume ratio is more scientific.
If shipping freight distribution by weight volume ratio is F01..... F0i..... F0n, as shown in (5).The $\mu$ can be adjusted according to the experience.

$$
\mathrm{F} 0 \mathrm{i}=(\mu \times \mathrm{VFi}+(1-\mu) \times \mathrm{WFi})
$$

\section{Shipping Freights Distribution Through Income}

The shipping freights distribution through income is distribution ratio to "Receiving freight". If the shipping freights distribution through income are $\mathrm{F}_{\mathrm{c} 1} \ldots \ldots . \mathrm{F}_{\mathrm{c} i} \ldots \ldots . \mathrm{F}_{\mathrm{cn}}$, the "Receiving freight" are $R_{1} \ldots \ldots R_{i} \ldots \ldots . R_{n}$. the shipping freights distribution through weight volume ratio and shipping freights distribution through income are more reasonable.The shipping freights distribution by income are as in (6).

$$
\mathrm{F}_{\mathrm{ci}}=\mathrm{F}_{0} \times \mathrm{R}_{\mathrm{i}} / \sum_{i=1}^{n} R
$$

\section{PICK ACCOUNT}

\section{A. Capital Management Data Flow}

Capital management data flow is as shown in Figure 1. The cashier fills out the temporary "Outbound balance lists" according to the transport agreement. After confirming, the date is imported into the " Daily settlement table ", the temporary "Outbound balance lists" is auto deleted. The 
account performs the pick account according to the "Balance sheet", after that, the corresponding data take part in operation in the " Daily settlement table" . " Daily settlement table" is the basic table, on which basis " Monthly settlement table " and " Annual settlement table " are created.

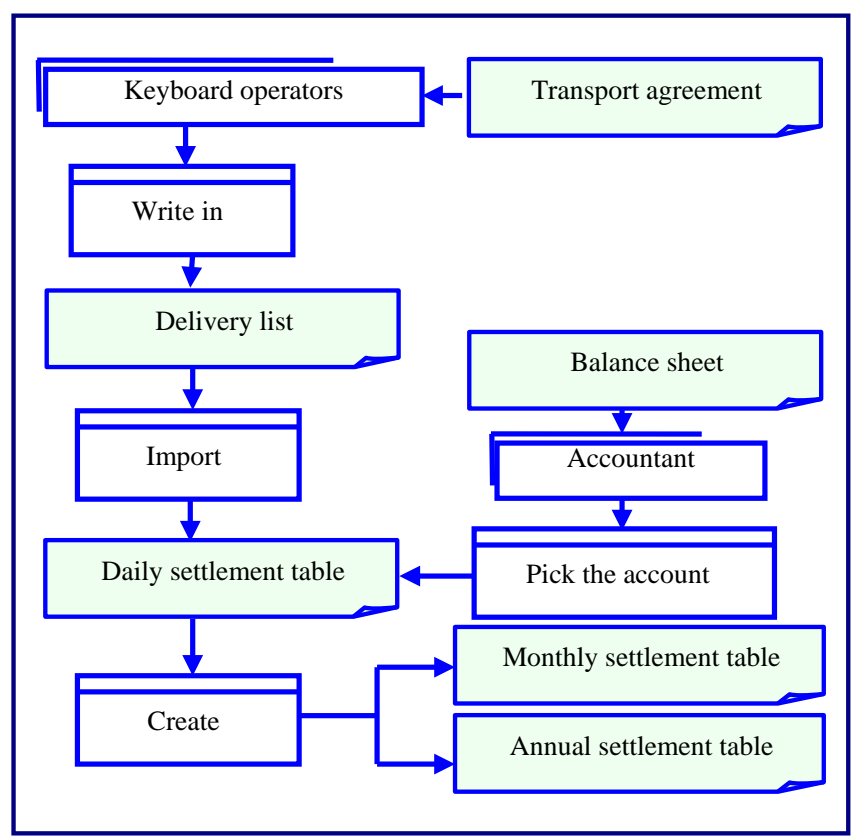

Figure 1. Capital management data flow.

\section{B. Pick Account}

"Settlement" items in the " Daily settlement table" include "Receiving freight Settlement" and "Shipping freight Settlement". When the "Receiving freight" is " Arrival pay ", "account period", " back pay ", which means the shipping companies have not received the shipping freight, this time the " Settlement " of " Receiving freight "should show [not], When the cost of " Receiving freight " has been settled with the shipping company, the accountant will replace [not] into [has been]。 The operation is called "pick account. Shipping freight " in the "Daily settlement table " is generated according to " Outbound balance lists " automatically. When the " Shipping freight " is " account period ", Shipping companies have not paid the shipping charges, this time the " Settlement " of " Shipping freight "should show [not]. When the cost is paid, the " Accountant " will replace [not] into [has been]. The operation is also called pick account.

After balancing the account, the payment clerk will hand the cash and "Balance sheet " over the cashier. The cash will be collected by the cashier and signed on the " Balance sheet ", then the " Balance sheet " is transferred to the accountant. The accountant will replace [not] into [has been] in the "Daily settlement table ", means " Arrival pay ", "account period", " back pay " is paid. The "Settlement" is to design logic in system. The " Settlement "amount of money participated in the "Enterprise fund balance table ${ }^{[10]}$ " operation. Accountant can replace "Settlement" only once, not reversible, the activation should prompt by the system. If "Receiving freight" or "Shipping freight" is cash, the "Settlement" will display [has been] default.

\section{SUMMARY}

This paper just provides the standardized process of logistics, the operation of outbound, Shipping freights distribution, Capital management data flow and Settlement algorithm at the place of departure in 4PL. When the cargo reached the destination there is still the standardized process of qualified acceptance, unqualified acceptance, Return goods of logistics Settlement algorithm, which will be discussed in another paper.

\section{ACKNOWLEDGEMENT}

This research was financially supported by program for Liaoning Innovative Research Team in University Liaoning Education Department(Grant NO. LT2013024).

\section{REFERENCES}

[1] Juan Ren The development of modern logistics information age. Management World. 2005, 11 : 152-153.

[2] CHU Xiao - jin. Study on Logistics Information Platform Based on the Needs of SMEs. LOGISTICS ENGINEE $R$ ING AND MANAGEMENT. $2014 . \quad 09 . \quad 026.71-72$.

[3] "The inform on accelerating the implementation of major projects of modern logistics " The National Development and Reform Commission [August 2015].

[4] Fan Ruguo, Li Yuying. Research on Cost Saving and Benefit Distribution of Logistics System Based on Fourth Party Logistics. Technology Economics.2010.11 : 127-131.

[5] Peng Yang, Liu Wei, Li Wenjuan. Research on the construction and operation mechanism of regional emergency logistics system Integrated platform. Logistics technology.2015.34v, No8(The first half).

[6] Yan Zhang, Qiong Sun, Yinghong Xie 4PL BUSINESS MODEL DESIGN BASED ON TPL REQUIREMENTS. ICEIS 2011 Thirteen International Conference on Enterprise Information Systems.702-707.

[7] Yan ZHANG , Yinghong XIE Research into 4PL Management Services Platform Based on Horizontal Supply Chain, ICLEM 2010: Logistics for Sustained Economic Development (C) 2010 ASCE, 45214527.

[8] Zhang Yan. The design thought based on the practical needs of multi-user 4PL platform . Logistics and Purchasing .2011.6.68-69.

[9] Yan Zhang, Qiong Sun. Design of Standardized Data Process in 4PL Freight Management. Education technology and information system. 42013icetis. 2013. 886-889.JN : Advances in Intelligent Systems Research.ISSN1951-6851.

[10] Yan Zhang, Zhonghu Yuan, Dongzheng WangProcess Design of Standardization Data for China 4PL Calculation Algorithm. 2016 International Conference on Communication, Business and Education. Communications, business and education. ISSN22513051.2016.1.P126-132. 